\title{
Spatial, temporal, and environmental influences on Atlantic cod Gadus morhua offshore recruitment signals in Newfoundland
}

\author{
Emma L. Lunzmann-Cooke ${ }^{1, *}$, Robert S. Gregory ${ }^{2,3}$, Paul V. R. Snelgrove ${ }^{1,3}$, \\ David Cote $^{1,2}$, César Fuentes-Yaco ${ }^{4}$ \\ ${ }^{1}$ Department of Ocean Sciences, Memorial University of Newfoundland, 0 Marine Lab Rd., St. John's, NL A1C 5S7, Canada \\ ${ }^{2}$ Ecological Sciences Section, Fisheries and Oceans Canada, 80 East Whitehills Rd, St. John's, NL A1A 5J7, Canada \\ ${ }^{3}$ Department of Biology, Memorial University of Newfoundland, 230 Elizabeth Ave., St. John's, NL A1C 5S7, Canada \\ ${ }^{4}$ Ecosystem and Ocean Sciences Sector, Fisheries and Oceans Canada, 1 Challenger Dr., Dartmouth, NS B2Y 4A2, Canada
}

\begin{abstract}
Numerous studies demonstrate the utility of information from coastal seine surveys for monitoring juveniles of Atlantic cod Gadus morhua, but few studies have linked such surveys to older ages within cohorts. We related juvenile (age-0 and -1) cod population components at a long-term monitoring site in Newfoundland to offshore pre-adult (age-3) cod recruitment at multiple spatial scales and explored some environmental and biological factors that affect juvenile-recruit relationships. Our models revealed significant relationships between juvenile and pre-adult abundance. The strength of these relationships varied with distance from nursery habitats and among fisheries management zones. Additionally, chlorophyll a concentration and body length during early life stages appeared to influence the strength of the relationship between juvenile and age-3 abundance. The potential to use juveniles as general indicators of future preadult abundance can aid in planning for low recruitment years and improve inferences about the response of cod population abundance to environmental changes. This study contributes to the growing body of knowledge demonstrating the utility of juvenile surveys in anticipating future year-class strength.
\end{abstract}

KEY WORDS: Year-class strength $\cdot$ Monitoring $\cdot$ Juvenile $\cdot$ Abundance $\cdot$ Nursery habitat $\cdot$ Coastal survey

\section{INTRODUCTION}

Many of the world's most valuable marine fish species (e.g. Atlantic cod Gadus morhua, Baltic Sea sprat Sprattus sprattus, herring Clupea harengus L.) exhibit strong recruitment variability, driven by a mixture of environmental and anthropogenic drivers that often leave fish populations vulnerable to depletion (e.g. Sætre et al. 2002, Stige et al. 2013, Rose \& Rowe 2015). Despite near ubiquitous commitments to maintaining ecologically sustainable fisheries, managers often face pressure to compromise decisions based on

\footnotetext{
${ }^{*}$ Corresponding author: emmallcooke@gmail.com
}

the socioeconomic impacts of sudden cuts to fishing quotas (Copes 1996). Fisheries managers have pursued better prediction of future recruitment for over a century (Hjort 1914) because improved projections would provide time to prepare for the socioeconomic and ecological effects of fluctuating fish stocks (Gulland 1989). Surveys of early life stages that improve understanding of recruitment variability could potentially contribute to adult stock assessments of many commercially valuable marine fishes by improving predictions of future stock strength (Sissenwine 1984, Houde 2008).

(C) E. L. Lunzmann-Cooke, P. V. R. Snelgrove and Fisheries and Oceans Canada 2021. Open Access under Creative Commons by Attribution Licence. Use, distribution and reproduction are unrestricted. Authors and original publication must be credited. 
Estimates of cohort strength in long-lived marine fishes often use adult abundance (e.g. spawning stock biomass, SSB; Stige et al. 2013) because many confounding factors (e.g. predation, advection, temperature) limit the utility of early life stages (e.g. eggs and larvae) for such estimates. Several studies have attempted to demonstrate a link between abundance of early life stages and adult fish in order to detect a 'recruitment signal' (Hjort 1914, Sissenwine 1984, Ings et al. 1997, Laurel et al. 2016). However, successful application of juvenile data to anticipate changes in adult abundance remains challenging for slower growing stocks, largely constrained by poor understanding of factors influencing juvenile survival and dispersal, and lack of long-term data series (e.g. Bradford 1992). Whereas several northeast Atlantic stock assessments, including cod (ICES 2017), integrate offshore pre-recruit indices, lack of understanding of empirical linkages between coastal pre-recruit and offshore adult life stages remains an obstacle to improved fisheries management more broadly (Sissenwine 1984, Skern-Mauritzen et al. 2016).

As expected, many studies report better predictions of year-class strength from recruitment for life stages sampled closer in time to age-at-recruitment (Stige et al. 2013, Laurel et al. 2017). Most researchers also consider juvenile fish surveys better predictors of future adult offshore recruitment than egg and larval surveys because juveniles are less vulnerable to predation and starvation, and easier to track (Stige et al. 2013). Furthermore, sampling difficulties (e.g. behaviour, advection) and unsuitable spatial coverage can limit accuracy of larval abundance and mortality estimates (Taggart \& Leggett 1987). Even beyond the larval stages, juveniles of many commercial fish species remain at substantial risk of high natural mortality, particularly in the absence of suitable nursery habitat (e.g. haddock Melanogrammus aeglefinus, Atlantic cod, walleye pollock Gadus chalcogrammus, and Nassau grouper Epinephelus striatus; Sissenwine 1984, Sogard \& Olla 1993, Jackson et al. 2001, Gillanders et al. 2003, Lilley \& Unsworth 2014). Although utilization of older age classes yields better predictions of future population estimates as a result of decreased vulnerability and sampling complications, forecasting population abundance further in advance using juvenile data would provide a considerable advantage to management, given the ecological and socioeconomic consequences of unexpected stock collapses.

The economic and ecological importance of Atlantic cod (hereafter cod) has provided impetus for numerous studies on factors that influence juvenile cod mortality and recruitment variability (e.g. Dae- wel et al. 2015, Horne et al. 2016, Laurel et al. 2017). Prior to the Northern cod fishery collapse and subsequent moratorium in 1992 (Taggart et al. 1994), juvenile cod yielded a weak but detectable recruitment signal on a rank-scale using data from a survey covering most of northeast coastal Newfoundland (Ings et al. 1997). Combining data from the pre-collapse period with data immediately post-collapse also produced a detectable recruitment signal on a ratio-scale from one year to the next (Ings et al. 1997). Furthermore, recent analysis of a short-term inshore survey, conducted in a similar northeast region of Newfoundland, identified a weak recruitment signal using age-0 abundance and a strong recruitment signal using age-1 abundance on a ratio scale (Laurel et al. 2017). Strong recruitment signals were similarly detected using age-1 indices of Atlantic and Pacific cod (G. morhua and G. macrocephalus) in Norway and Alaska (Laurel et al. 2017). However, the lack of longduration time series for juveniles of many populations has generally compromised statistical efforts to link early life stages of cod to recruitment variability.

Extreme vulnerability in juvenile cod throughout the first few years of life may interact with environmental and spatio-temporal factors to confound patterns and strength of observed predictive relationships with recruitment. Factors that contribute to variable survival and predictive ability include nursery habitat availability (Tupper \& Boutilier 1995a, Warren et al. 2010), water temperature (Copeman et al. 2008), growth and body size (Tupper \& Boutilier 1995b, Drinkwater 2005), productivity levels (e.g. phytoplankton blooms) (Kristiansen et al. 2011), and the presence of other fishes that may act as competitors, predators, or prey (Linehan et al. 2001, Laurel et al. 2003a). Analyses of interactions between environmental factors using time series data with high interannual variation in juvenile abundance may prove useful in forecasting year-class strength in cod.

Since its collapse in the early 1990s, the Northern cod population off Newfoundland and Labrador has been slowly rebuilding, coinciding with spatial redistributions in offshore environments (deYoung \& Rose 1993, DFO 2016, Rose \& Rowe 2018). However, variation in predictive strength with spatial scale and the spatial extent of recruitment signals from a juvenile index site remain poorly understood for this stock. Spatial considerations may be important for anticipating stock strength given the substantial distributional shifts caused by movement from juvenile to adult habitats. Multiple studies have explored spatiotemporal variability and stability in recruitment in marine fish populations (e.g. Sale et al. 1984, Stige et 
al. 2013). Determining the sources of variability in recruitment signals will enhance their utility in projecting good years versus poor years.

We investigated the potential for nearshore seine surveys to detect recruitment signals in pre-adult cod abundance in coastal Newfoundland at multiple spatial scales. Our study focused on determining whether an empirical link exists between juvenile and pre-adult abundance of cod to allow anticipation of good versus poor year classes. Using an extensive time series dataset, we hypothesized that a recruitment signal would vary in relative strength over different spatial scales. We examined how the strength of recruitment signals varied with distance from the index site. Furthermore, we hypothesized that consideration of select environmental and biological factors in tandem with juvenile abundance would strengthen the link to recruitment.

\section{MATERIALS AND METHODS}

\subsection{Model input variables}

\subsubsection{Juvenile abundance (age-0 and -1)}

Juvenile cod in Newman Sound, Bonavista Bay off the northeast coast of Newfoundland (Fig. 1) have been monitored extensively over a 25-yr period (beginning in 1995, Gregory et al. 2016), creating a rare long-duration dataset on juvenile fish. The study area includes 12 nearshore sites, initially chosen based on presence of cod nursery habitat (Gregory et al. 2016). Each site was sampled biweekly from July to November using seine hauls to determine abundances of fish species inhabiting nearshore habitats. We analyzed all data from a total of 2381 seine hauls conducted in all but one year (1997) between 1996 and 2015; the

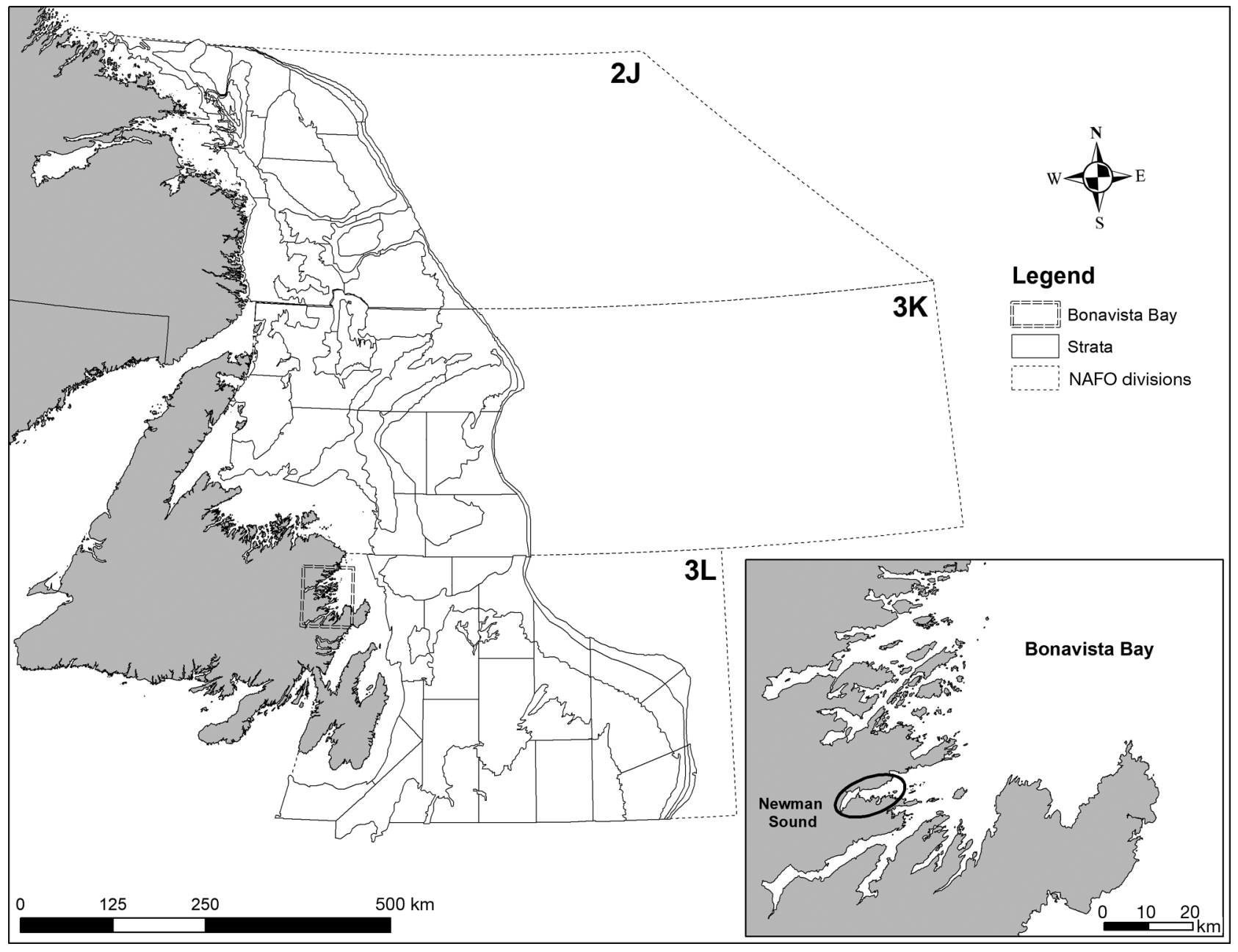

Fig. 1. Location of Newman Sound (oval in inset) and Bonavista Bay with respect to Northwest Atlantic Fisheries Organization (NAFO) fisheries management divisions 2J3KL and strata off the northeast coast of Newfoundland 
survey did not occur in 1997. On average, our analysis included 23.8 seine hauls for each month.

Fish were sampled using a Danish bag seine $(25 \times 2 \mathrm{~m} ; 9 \mathrm{~mm}$ mesh) deployed using a small, motorized boat (see Gotceitas et al. 1997 for details). Each deployment sampled a total area of $880 \mathrm{~m}^{2}$ and included the lowermost $2 \mathrm{~m}$ of the water column. One seine haul was performed at each site within $2 \mathrm{~h}$ of low tide, during daylight hours at periods of peak neap and spring tides (i.e. biweekly). All fish species caught were identified, counted, measured to standard length (mm SL) and then released. We assigned tentative ages to all juvenile cod using pre-established length-age classes from the northeast Newfoundland coast (Dalley \& Anderson 1997). These ages were corrected where necessary by examining length frequencies of each year-class and, in some years, using otolith microstructure to validate estimates of lengthage classes. Biweekly sampling meant we could follow cohorts through time within seasons, reducing the need for age validation.

All sites contained a mixture of bottom habitat with macrophytes such as eelgrass Zostera marina, kelp, and rockweed overlaying mineral-based substrates such as cobble, sand, and mud. Proportions of each habitat type varied among sites and among years. We estimated the proportion of eelgrass coverage for each site annually using visual site inspections, aerial photos, or scuba transects (1996-2015).

Daily mean water temperatures $\left( \pm 0.1^{\circ} \mathrm{C}\right)$ were calculated from 1995 to 2015. We used Vemco Mini-T (or Mini-T-II) thermographs to record water temperature hourly from 2002 to 2015 and Hugrun thermographs from 1995 to 2001, recording every $4 \mathrm{~h}$ at 4 standardized locations in Newman Sound. Thermographs were suspended $50 \mathrm{~cm}$ above the bottom at a depth of approximately $3 \mathrm{~m}$. Daily water temperatures indicated minimal variation among sampling locations.

\subsubsection{Chlorophyll a concentration}

The role of primary production in recruitment was assessed using peak phytoplankton biomass data (using chl a concentration as a surrogate for biomass) based on satellite imagery (GlobColour 2007). We calculated phytoplankton biomass using the Garver, Siegel, and Maritorena (GSM) semi-analytical biooptical model (Maritorena \& Siegel 2005, Maritorena et al. 2010). Analysis of phytoplankton blooms and development of biological points of interest were performed by applying an optimization of para- meters on a split Gaussian curve to the satellitederived points (Fuentes-Yaco et al. 2020). Spring and autumn peak chl a concentrations $\left(\log _{10}\left(\mathrm{mg} \mathrm{m}^{-3}\right) \mathrm{d}^{-1}\right)$ were estimated for Bonavista Bay (which includes Newman Sound), at a spatial resolution of $4 \mathrm{~km}$ for $12 \mathrm{yr}$ of available data (2003-2014).

\subsubsection{Pre-adult abundance (age-3)}

The Northern cod stock encompasses the area off the northeast coast of Newfoundland and Labrador in Northwest Atlantic Fisheries Organization (NAFO) zones 2J3KL (Fig. 1). For this stock, 'recruitment' can be defined as the abundance of age- 3 cod in the survey area - the youngest age at which the trawl survey effectively samples cod. Our estimates of annual abundance of age- 3 cod were based on the results of ca. 7150 trawls (1998-2016), obtained from the Fisheries and Oceans Canada (DFO) fall research vessel (RV) survey, conducted annually at some time between October and January, depending on the year. The annual 2J3KL stock assessment utilizes the DFO fall RV survey as its primary data source.

DFO began using a Campelen 1800 shrimp trawl in the Newfoundland region in 1995 to complete all bottom trawl surveys. Rigid standardization of bottom trawl survey and fishing protocols was implemented to ensure consistent trawl performance (see Walsh \& McCallum 1997 and Walsh et al. 2009 for full information on protocols). Trawls occurred in areas ranging from 57 to $499 \mathrm{~m}$ in depth among the 57-74 index strata (<500 m depth) sampled each year. Each stratum was sampled at least twice, with total trawl sets across strata varying from 274 to 329 annually.

\subsection{Data analyses}

\subsubsection{Recruitment signals}

We investigated the strength of the relationship between juvenile abundance (age- 0 and -1) in the nearshore and age- 3 abundance in the offshore in northeastern Newfoundland. We used well-established statistical linear modelling approaches previously used to investigate recruitment signal strength (e.g. Stige et al. 2013, Laurel et al. 2016, 2017). In order to determine a link, we followed the same cohort through time. For example, we compared age0 abundance in 1996 to age-1 abundance in 1997, and age-3 abundance in 1999. 
Abundance of juvenile cod in beach seines was compared against abundance of age-3 cod from the DFO RV Survey. Noting that our data represent counts and were overdispersed, we used a negative binomial generalized linear model (GLiM) with a log link to assess the relationship between juvenile and age- 3 cod abundance $\left(\mathrm{n}_{\text {Age- } 0}=17, \mathrm{n}_{\text {Age- } 1}=18\right)$. No constants were added to juvenile abundance indices for models assessing the relationship with age-3 abundance. All models followed the same general form, demonstrated here with age- 0 and age- 3 abundance:

$$
\begin{gathered}
\operatorname{Cod}_{\text {Age- } 3}=\mathrm{e}^{\mathrm{n}} \\
\mathrm{n}=\alpha+\beta_{1} \operatorname{cod}_{\text {Age- } 0}
\end{gathered}
$$

After examining the residuals, we considered a general linear model (GLM), a subset of GLiMs, more acceptable to assess the relationship between age-0 and age-1 cod. We therefore used a GLM with a normal error structure to investigate the relationship between age-1 abundance and age-0 abundance ( $\mathrm{n}=18$ ), $\log$ transforming the abundance of age- 0 and age-1. For this analysis, we added a constant of 1 to juvenile abundance indices to account for the presence of zeros, and we set statistical significance at alpha $=0.05$. All models followed the same general form for age-0 and age-1 abundance:

$$
\log \left(\operatorname{cod}_{\mathrm{Age}-1}+1\right)=\alpha+\beta_{1} \log \left(\operatorname{cod}_{\mathrm{Age}-0}+1\right)
$$

Model residuals demonstrated that all assumptions were met, and we present diagnostic plots in the Supplement (see Figs. S1-S3 at www.int-res.com/ articles/suppl/m673p151_supp.pdf). Recruitment signal strength was assessed using the adjusted coefficient of determination $\left(\mathrm{R}^{2}\right)$ of the model for GLMs and adjusted explained deviance (adjusted $\mathrm{D}^{2}$ ) for the GLiMs, calculated as:

$$
\begin{aligned}
\mathrm{D}^{2}= & \frac{\text { (null deviance }- \text { residual deviance })}{\text { null deviance }} \\
& \text { Adjusted } \mathrm{D}^{2}=1-\frac{\mathrm{n}-1}{\mathrm{n}-\mathrm{p}} \times\left(1-\mathrm{D}^{2}\right)
\end{aligned}
$$

Adjusted $\mathrm{D}^{2}$, the amount of deviance accounted for in a GLiM, provides a measure of goodness of fit while accounting for the number of observations (n) and parameters (p) in a model (Guisan \& Zimmermann 2000). Negative adjusted $D^{2}$ values can occur in cases with large numbers of model variables and poor fit. We set such negative adjusted $\mathrm{D}^{2}$ values to zero to signify the lack of model fit. Considering it may only be feasible to conduct juvenile surveys once or twice per year, we ran each model using ju- venile data from the entire sampling period (July to November) and each month separately to determine the sampling period with the best model fit.

\subsubsection{Spatial scale analysis}

To assess how recruitment signals from juvenile survey locations changed with distance, we ran each model using age-3 abundance in spatial buffers progressively increasing in radius at $50 \mathrm{~km}$ intervals, centred on Newman Sound, until we covered the entire 2J3KL management area (i.e. buffers $=100,150, \ldots, 850$ km, Fig. 2). Successive buffers were aggregated in a cumulative fashion starting from the juvenile survey area. We also examined recruitment signal strength among NAFO management areas by separating age-3 abundance within $2 \mathrm{~J}, 3 \mathrm{~K}$, and $3 \mathrm{~L}$.

\subsubsection{Environmental and biological factors}

We also examined the potential influence of environmental and biological factors on the relationships between juvenile abundance and age-3 abundance. This was done by including environmental and biological factors as interaction terms with juvenile abundance in separate GLiMs. Environmental and biological variables were included separately so that models were not over-parameterized. We represented these additional environmental and biological factors as annual values and included 2 seasonal water temperature anomalies (summer and autumn, and winter), winter duration, mean standard body length, mean percent eelgrass cover, and peak autumn and spring chl a concentration. We calculated juvenile body length for both age-0 and age-1 cod as the mean standard length (mm SL) of each age class in each year of the time series for the month showing the strongest recruitment signal (November and October for age-0 and age-1, respectively). We calculated winter duration as the number of days when mean daily water temperature did not exceed $1^{\circ} \mathrm{C}$. Seasonal water temperature anomalies were calculated for the juvenile settlement period during the summer and autumn (July-November) and winter (days when water temperature did not exceed $1^{\circ} \mathrm{C}$ ). Using data from 1995 to 2015 , we calculated the baseline temperature and temperature anomalies. Depending on data availability, the residual degrees of freedom varied among the models containing environmental factors. All GLiMs followed the same 


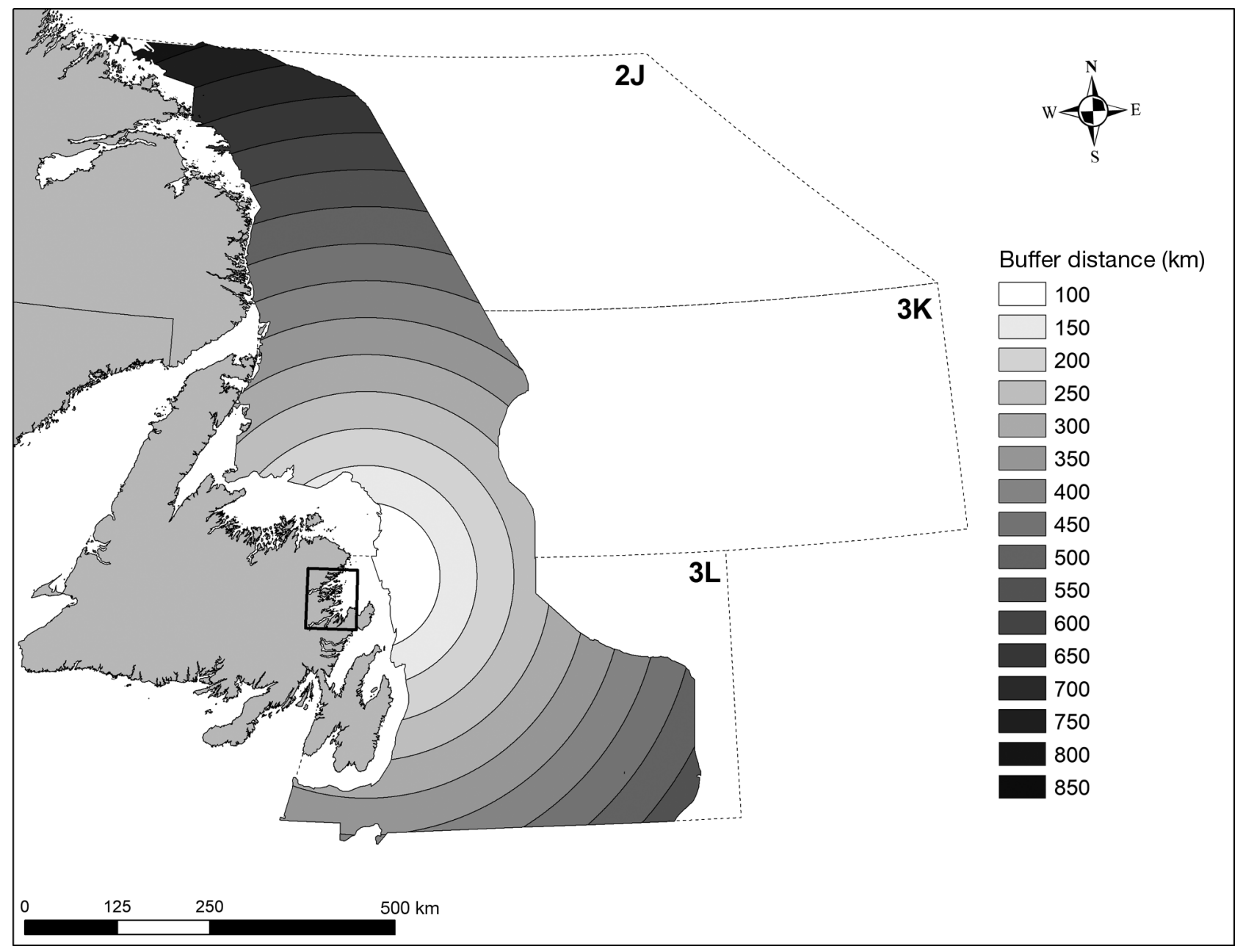

Fig. 2. Buffers (100-850 km) within Northwest Atlantic Fisheries Organization (NAFO) divisions 2J3KL centred on Newman Sound, Bonavista Bay (rectangle) used for spatial analysis of recruitment models

general form, demonstrated here for age-3 and age-0 abundance, and winter water temperature:

$$
\begin{gathered}
\operatorname{Cod}_{\text {Age }-3}=\mathrm{e}^{\mathrm{n}} \\
\mathrm{n}=\alpha+\beta_{1} \operatorname{cod}_{\text {Age- } 0}+\beta_{2} \text { temp }_{\text {wint }} \\
+\beta_{3} \operatorname{cod}_{\text {Age- } 0} \text { temp } \\
\text { wint }
\end{gathered}
$$

All statistical analyses were conducted in $\mathrm{R}$ version 3.4.3 (R Development Core Team 2017).

\section{RESULTS}

\subsection{Recruitment signals}

Juvenile surveys conducted later in the autumn yielded stronger recruitment signals than those conducted earlier in the year. For the age- 0 to -3 model, abundance in November yielded the strongest re- cruitment signal across the entire stock area (Fig. 3). For the age- 1 to -3 model, abundance in October yielded the strongest recruitment signal across the entire stock area (Fig. 3). Therefore, we used November data for age-0 abundance and October data for age- 1 abundance values for the remainder of the analyses. The model comparing age- 0 to -1 abundances (log transformed +1 ) produced a strong recruitment signal (adjusted $\mathrm{R}^{2}=0.524$, $\mathrm{p}<0.001$; Fig. 4A, Table S7). The model comparing age- 0 and age- 3 abundance produced a slightly stronger recruitment signal (adjusted $\mathrm{D}^{2}=0.355, \mathrm{p}=$ 0.004; Fig. 4B, Table S1) than the age-1 to -3 model (adjusted $\mathrm{D}^{2}=0.277, \mathrm{p}=0.006$; Fig. $4 \mathrm{C}$, Table S2). All models were statistically significant $(p<0.05$; Table 1). When juvenile cod were abundant, subsequent recruitment offshore varied greatly. However, during periods of low juvenile cod abundance, 
these year classes were consistently weak offshore (Fig. 4B,C).

\subsection{Spatial scale analysis}

For all models, recruitment signals generally strengthened with increasing distance from the juvenile survey area (Newman Sound, Bonavista Bay). The $350 \mathrm{~km}$ buffer yielded the strongest recruitment signal for age-0 (adjusted $\mathrm{D}^{2}=0.359, \mathrm{p}=0.004$ ); however, the $850 \mathrm{~km}$ buffer (encompassing the entire NAFO 2J3KL survey area) yielded a similar recruitment signal (adjusted $\mathrm{D}^{2}=0.355, \mathrm{p}=0.004$; Fig. 5A, Table S1). Similarly, the $750 \mathrm{~km}$ buffer yielded the strongest recruitment signal for age-1 (adjusted $\mathrm{D}^{2}=$ $0.278, \mathrm{p}=0.007$ ), although the recruitment signals were almost identical from 600 to $850 \mathrm{~km}$ (Fig. 5A, Table S2). For the age-0 to -3 model, the recruitment signal was strongest in NAFO divisions $2 \mathrm{~J}$ (adjusted $\mathrm{D}^{2}=0.408, \mathrm{p}=0.001$ ) and $3 \mathrm{~K}$ (adjusted $\mathrm{D}^{2}=0.460, \mathrm{p}<$ 0.001), in contrast to a non-significant recruitment signal in 3L (adjusted $\mathrm{D}^{2}<0.001, \mathrm{p}=0.682$; Fig. 5B,

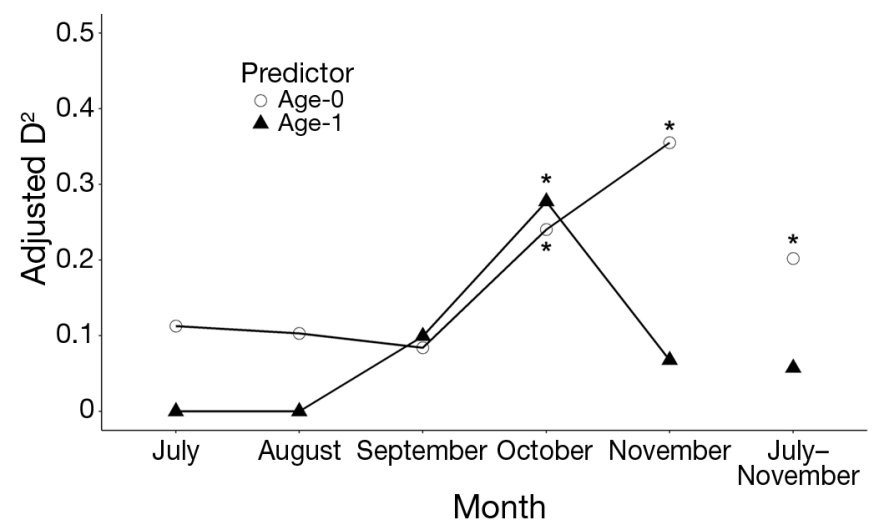

Fig. 3. Age-3 recruitment signal strength (adjusted $\mathrm{D}^{2}$ ) based on juvenile abundance (mean catch per haul) averaged for each month and over the entire season (i.e. July-November) for predictor age classes (age- 0 and age-1). Asterisks (*) indicate statistically significant periods $(\mathrm{p}<0.05)$
Table S3). Likewise, for the age-1 to -3 model, NAFO divisions 2J (adjusted $\mathrm{D}^{2}=0.417, \mathrm{p}<0.001$ ) and $3 \mathrm{~K}$ (adjusted $\mathrm{D}^{2}=0.314, \mathrm{p}=0.002$ ) also yielded the strongest recruitment signal, with a very weak, non-significant recruitment signal in 3L (adjusted $\mathrm{D}^{2}<0.001, \mathrm{p}=0.731$; Fig. 5B, Table S4).
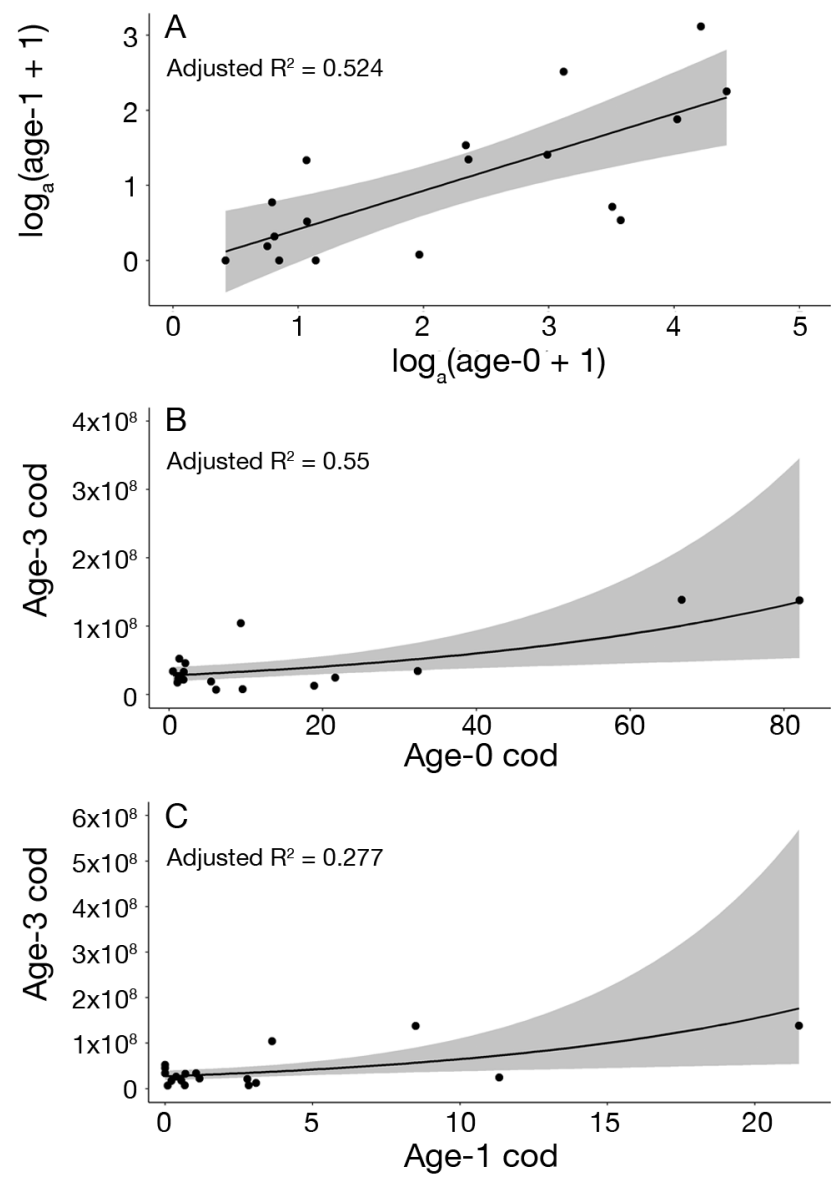

Fig. 4. Recruitment signals between mean juvenile cod (age-0 and -1) abundance (mean catch per haul) in Newman Sound, Bonavista Bay and pre-adult (age-3) cod abundance in Northwest Atlantic Fisheries Organization (NAFO) divisions 2J3KL $( \pm 1.96 \mathrm{SE})$. (A) Age-0 and $-1\left(\log _{\mathrm{e}}\right.$ transformed +1$) ;(B)$ age- 0 and -3 ; (C) age- 1 and -3

Table 1. Summary of (A) generalized linear model (negative binomial with a log link) results for recruitment signals of age-3 cod abundance in NAFO divisions 2J3KL (abundance within $850 \mathrm{~km}$ of the juvenile survey area) using age-0 and age-1 cod abundance (mean catch per haul), and (B) general linear model results for the relationship between November age-0 abundance and October age-1 abundance in Newman Sound, Bonavista Bay (mean catch per haul; both log-transformed +1 )

\begin{tabular}{|c|c|c|c|c|c|c|}
\hline & Response & Predictor & Estimate & df & $\mathrm{p}$ & Model fit \\
\hline (A) & Age-3 abundance & Age- 0 abundance & 0.019 & 1,15 & 0.004 & Adjusted $\mathrm{D}^{2}=0.355$ \\
\hline (A) & Age-3 abundance & Age-1 abundance & 0.087 & 1,16 & 0.006 & Adjusted $\mathrm{D}^{2}=0.277$ \\
\hline (B) & Age-1 abundance & Age-0 abundance & 0.513 & 1,16 & $<0.001$ & Adjusted $\mathrm{R}^{2}=0.524$ \\
\hline
\end{tabular}



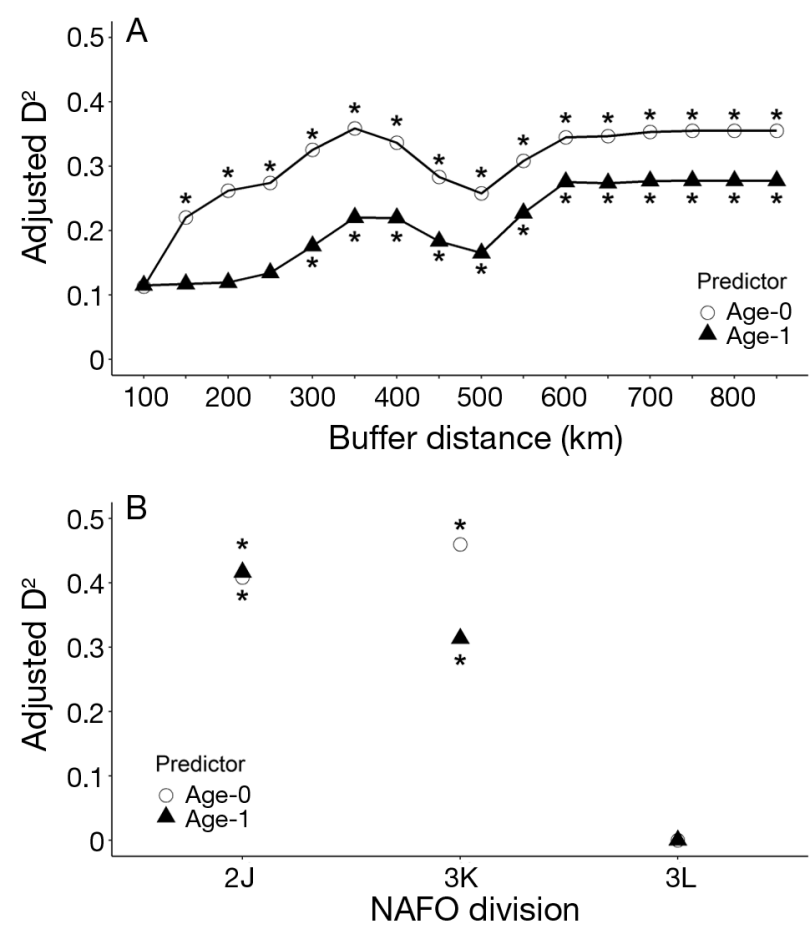

Fig. 5. Age-3 recruitment signal strength (adjusted $D^{2}$ ) from juvenile abundance (mean catch per haul) (A) with increasing distance from nursery habitat, and (B) across Northwest Atlantic Fisheries Organization (NAFO) divisions. Relationships denoted by asterisks $\left(^{*}\right)$ are statistically significant $(\mathrm{p}<0.05)$

\subsection{Environmental and biological factors}

The only environmental and biological variables with a significant interaction with juvenile abundance were autumn chl $a$ level and mean body length (mm SL). Peak autumn chl a level interacted positively with age-1 abundance (adjusted $\mathrm{D}_{\text {model }}^{2}=0.458, \mathrm{p}=0.024$; Table S6). Mean age-0 body length in November interacted significantly and positively with age-0 abundance (in November) (adjusted $\mathrm{D}^{2}$ model $=0.639, \mathrm{p}=$ 0.006; Table S5). No additional variables improved the relationship between age- 0 and age- 1 cod (log transformed + 1) (Table S7). Seasonal water temperature anomalies, peak spring chl a level, winter duration, and percent eelgrass cover had no influence on any relationships ( $p>0.05$; Tables S5 \& S6). There were no strong ecological or statistical correlations among our environmental variables.

\section{DISCUSSION}

We identified recruitment signals between 2 early age abundances and the offshore population of cod.
As predicted, we detected a recruitment signal between early ages (age-0 and age-1) in Newman Sound and offshore pre-adult cod (age-3) in Newfoundland's NAFO divisions 2J3KL. All recruitment signals were strongest during October and November, when abundance was often highest and range of fish sizes was often greatest. High abundance of age-0 likely results from multiple settlement 'pulses' arriving throughout the summer and autumn as a result of wind and upwelling events (Ings et al. 2008, Gregory et al. 2016), which often indicates a strong cohort. Multiple settlement pulses help to reduce intraspecific competition by staggering sizes of new recruits within a season and reduce the risk of mortality to an entire year class from predation, environmental stressors, or mismatch with prey (Kristiansen et al. 2011). However, our study did not consider pulse structure empirically. Furthermore, both age- 0 and -1 abundances were high in the autumn because winter migrations to deeper, warmer water typically occur later in the year (Cote et al. 2001, 2004).

Juvenile cod often remain in a given habitat type, exploring a small home range and maintaining high site fidelity (Pihl \& Ulmestrand 1993, Cote et al. 2004). High site fidelity of juveniles and sampling the same locations each year likely contributed to strong recruitment signals between age- 0 and age- 1 cod by minimizing spatial variation in abundance. The strong relationship between age- 0 and age- 1 abundance confirms our expectation of a greater disconnect between juvenile and age-3 abundance. We predicted weaker recruitment signals between juvenile and age- 3 abundance because of the temporal ( $\geq 2 \mathrm{yr}$ ) and spatial separation that we expected would complicate the detection of recruitment signals among the life stages we investigated. Off the northeast coast of Newfoundland, juvenile cod often remain close to their coastal nursery habitats for several (2-3) years, eventually migrating into deeper water (Templeman 1974, Gregory \& Anderson 1997, Cote et al. 2004). Therefore, differences in sampling location and survey gear likely contribute to the unexplained variance in age-3 abundance. Spatial differences in the nearshore distribution of juveniles, where seine surveys work most effectively (Gotceitas et al. 1997), and offshore distributions of older individuals (Tulk et al. 2017), where bottom trawls provide density estimates, complicate comparisons across methods.

Unexpectedly, recruitment signal strength decreased using age classes closer to recruitment (i.e. age-1 compared to age-0). Poorly sampled age-1 abundance, leading to underrepresentation of the age class in Newman Sound, may have weakened 
the recruitment signals in the age- 1 to age- 3 model (Rogers et al. 2011). Seine surveys represent age-1 cod abundance better than offshore surveys due to the presence of age-1 cod in nearshore habitats, but habitat use in nearshore areas may also change with ontogeny and variation in environmental conditions among years (e.g. Bradbury et al. 2008, Rogers et al. 2011, Cote et al. 2013). Age-0 cod occur most commonly in shallow nearshore areas containing nursery habitat such as eelgrass (Gotceitas et al. 1997, Laurel et al. 2003b), which occur locally mainly within the seine haul sampling area. Age-1 cod may occur outside of the seine haul area in deeper habitats for reasons such as avoidance of unfavourable water temperatures and predators, population density, and diel migrations (Methven \& Bajdik 1994, Robichaud \& Rose 2006, Cote et al. 2008, Espeland et al. 2010) reducing their predictive utility if only sampled in shallow habitats. These considerations suggest that early life stages likely provide the most suitable metric of relative recruitment success among cohorts. Although strong year-class strength in juveniles may not always translate into high offshore abundance, the relationship between poor year-class strength and low offshore abundance is much more evident. Thus, data on juveniles could provide fisheries managers with advance warning of low recruitment years and allow them to prepare for socioeconomic effects.

\subsection{Spatial scale analysis}

Identifying the origin of recruits in inshore and offshore regions remains a challenge with assessing many marine fishes (André et al. 2016). From the late 1980 s to the mid 1990 s, offshore populations of cod declined catastrophically, and the remaining smaller aggregations occurred inshore (DFO 2016). However, in recent years, cod have greatly expanded their distribution across the Newfoundland Shelf, and fisheries managers continue to calculate a single annual value of abundance for the entire 2J3KL NAFO fisheries management region (DFO 2016). We examined how recruitment signals changed with increasing distance from juvenile monitoring sites. We were interested in whether fluctuations in Newman Sound juvenile abundance were reflected in subsequent recruitment across the entire offshore, or if certain spatial scales or management zones revealed a stronger statistical link. For all models, recruitment signals were generally strongest within the largest buffers (i.e. the majority of the 2J3KL NAFO area). With limited tagging and genetic data, the dispersal, migration, and location of recruits in the offshore remain largely unknown. However, a recent genetic study revealed a sibling relationship and broad relatedness between cod spanning management zones along the Newfoundland coast (Horne et al. 2016). Also, cod in both the inshore and offshore regions of Newfoundland exhibit different migratory behaviours within and among regions (e.g. resident vs. migratory), seasonal intermingling, and genetic distinction (Ruzzante et al. 1996, Brattey 1999, Robichaud \& Rose 2004, Brattey et al. 2008). These studies may explain why a broad survey area showed the strongest recruitment signal, in that it better represented the many different aggregations and subpopulations of Atlantic cod within the population area. Strong recruitment signals have been reported based on inshore abundance (Laurel et al. 2017); unfortunately, no abundance data were available for the coastal zone $(<30 \mathrm{~km}$ from shore) at a comparable time scale with which we could explore these ideas. Based on our analyses, Newman Sound juvenile abundance has utility in identifying low recruitment years for the entire offshore.

However, using age-3 abundance from $2 \mathrm{~J}$ and $3 \mathrm{~K}$ as the response variable improved the recruitment signal for all models compared to using abundance from the entire 2J3KL region. Despite moderately high correlations in abundance between 2J3KL zones (Tulk et al. 2017), the recruitment signal for 3L was weak and non-significant. Since the cod collapse in the late 1980s and early 1990s, 3L has yielded a lower abundance of cod than $2 \mathrm{~J}$ and $3 \mathrm{~K}$. Higher concentrations of cod are often found in offshore regions within 2J and 3K (Mello \& Rose 2008, Rose \& Rowe 2015, DFO 2016). Cod population recovery in 3L has also been the slowest among those areas we examined (DFO 2016), likely dampening the aggregate recruitment signal. Dominating ocean currents (Davidson \& deYoung 1995) and onshore winds critical to post-larval settlement in cod nurseries (Ings et al. 2008) likely also explain the lack of coherence between Newman Sound and 3L despite their geographic proximity.

\subsection{Environmental and biological factors}

Investigations of interacting and additive effects of environmental variables on fish abundance have become increasingly common in response to changing climate and slow recovery of commercial populations (e.g. Britten et al. 2016, Zhang et al. 2016). Indeed, environmental variables can explain substantial variability in recruitment models (e.g. Zabel 
et al. 2011). In our study, there is a significant positive interaction effect of peak autumn chl a concentration and age- 1 abundance on age- 3 cod abundance. This result indicates a stronger relationship between juvenile and pre-adult cod in years with high peak chl a concentration than those with low peaks. This observation was not unexpected. High concentrations of chl a (phytoplankton) enhance zooplankton production which acts as a food source for early stages of cod (Lomond et al. 1998, Beaugrand et al. 2003, Kristiansen et al. 2011) and likely improve survival and enhance the strong relationship between juveniles and age-3 pre-adult recruits. Although no data were available in our study region to investigate levels of secondary productivity, we suggest a reasonable likelihood that primary and secondary productivity correlate strongly. Previous studies relate cod stock biomass and primary productivity to a positive link between primary productivity, secondary productivity, and benthic food sources for age-1+ juvenile cod (Steingrund \& Gaard 2005). In the autumn, greater plankton production relative to summer likely promotes high growth, reducing the time juveniles are vulnerable to predators and starvation (Lomond et al. 1998, Beaugrand et al. 2003). At low densities of juvenile cod, the magnitude of the phytoplankton bloom may not act as the primary influence on juvenile growth and survival; however, at higher densities, available food presumably becomes increasingly important in reducing competition for resources.

Surprisingly, we did not observe a positive influence of primary productivity on the relationship between age- 0 and age- 3 cod. Phytoplankton blooms benefit age-0 fish in ways that vary annually (Hjort 1914, Sissenwine 1984, Cushing 1990, Platt et al. 2003, Ings et al. 2008). Further, the timing and magnitude of the autumn bloom may also influence prey of juveniles, noting size-associated prey requirements (e.g. age-1 and age-0 cod, Lomond et al. 1998). Similarly, food web dynamics prior to winter may affect adult condition, potentially enhancing the condition and reproductive output of adults with little concurrent effect on age-0 juveniles (e.g. haddock, Friedland et al. 2008, Leaf \& Friedland 2014). These often stochastic factors influence the strength of links between age- 0 and age- 1 cod and older age classes, even within single cohorts. Notably, unlike the spring bloom, few studies regularly measure or report the magnitude of the autumn bloom (DFO 2019). Satellite remote sensing now enables such analysis. As shown in our study, and other studies conducted in adjacent geographic regions, using bloom mag- nitude can greatly increase our understanding of fish population strength and interannual variability (Johnson et al. 2018, Fuentes-Yaco et al. 2020).

We also detected a significant and positive interaction between age- 0 body length and age- 0 abundance interaction effect on age-3 abundance. Favourable growth conditions support faster individual growth and greater accumulation of lipid stores (Otterlei et al. 1999, Planque \& Fredou 1999, Copeman et al. 2008, Laurel et al. 2017). Faster growth leads to increased body size, thereby increasing the ability of juvenile fish to avoid predators. It also reduces chances of starvation during periods of low productivity and food availability, such as winter (Copeman et al. 2008, Geissinger et al. 2021). Although the potential response of cod to future climate change remains largely unknown, a recent study by Laurel et al. (2017) demonstrated the importance of temperaturedependent growth potential in estimating recruitment signals in 3 locations with known cod populations: Newfoundland, Alaska, and Norway. Their study found improved recruitment signals during favourable growth conditions in the settlement period before the first winter (i.e. age-0), when juveniles are highly susceptible to variations in food availability (Geissinger et al. 2021). Age-0 cod likely benefit from faster growth and increased chances of survival before they enter their first winter, when high mortality likely occurs. Our results contribute evidence suggesting growth and body size-at-age are indicative of adult abundance (Campana 1996, Laurel et al. 2017).

Surprisingly, we found no significant interaction between juvenile abundance and eelgrass through the entire time series. Eelgrass, considered an ecologically significant species (DFO 2009), occurs commonly along the coast of Newfoundland, but is vulnerable to anthropogenic and environmental stressors such as fishing activity and ice scour (DFO 2009, Warren et al. 2010). Although juvenile cod live within many structured habitats (e.g. cobble, rocky reefs, kelp etc.), they benefit from eelgrass beds through increased refuge (Gotceitas et al. 1997, Laurel et al. 2003a) and greater prey abundance (Renkawitz et al. 2011), ultimately leading to higher juvenile (age-0) density in eelgrass beds compared to unvegetated areas (Cote et al. 2013). Although several studies show positive effects of eelgrass presence on local juvenile cod survival and abundance (e.g. Laurel et al. 2003a, Gorman et al. 2009, Thistle et al. 2010, Cote et al. 2013), expanding eelgrass cover and low interannual variability meant that our analyses did not identify eelgrass as a primary influence on age- 0 to age- 3 recruitment signals. 
Interestingly, no variables other than juvenile abundance increased our understanding of the relationship between age-0 and age-1 cod. This result was unexpected. It is possible that the impacts of the variables we tested in this study begin at younger life stages but only manifest after age-1. We suggest further study on how environmental and biological variables play a role in modelling year-class strength. Our results are also consistent with past studies indicating that the magnitude of environmental effects may interact with and depend on population density (Zabel et al. 2011, Ottersen et al. 2013). Cooke (2019) also conducted exploratory analyses of recruitment signal variation over multiple time periods throughout our time series and the impact of predator and prey abundance on recruitment signal strength, but found no clear patterns. Consideration of environmental variables remains an important part of interpreting year-class strength in juvenile cod and forecasting adult abundance.

Our study provides empirical evidence of the utility of information from nearshore seine surveys for juvenile fish in predicting poor recruitment to offshore fisheries. As expected, we detected a recruitment signal between Newman Sound coastal nursery habitats and the pre-adult Northern cod population offshore. Recruitment signal strength varied among fisheries management zones and with distance from juvenile cod nursery habitats. We identified additional biotic and abiotic factors that appear to play a role in recruitment to the fishery: peak autumn concentration of chl $a$ and juvenile body length. Environmental variables should be considered when attempting to maximize predictive ability of this approach across fish populations. Our results emphasize the value of longduration ecological time series to fully understand the role of environmental factors on recruitment over time. The Northern cod stock currently remains at a historic low and we must necessarily hinge our results on very few high recruitment years. Our current results highlight the utility of juvenile data to forecast low recruitment years, acknowledging a less clear relationship between strong year-class strength and high recruitment. Ultimately, these findings support the incorporation of juvenile abundance into assessments, but also highlight the complexity of juvenileadult prediction and the associated challenges of applying juvenile abundance data when forecasting fluctuations in stock abundance.

Acknowledgements. The National Sciences and Engineering Research Council of Canada (NSERC), the Dr. Wilfred Templeman Memorial, and Commander Peter G. Chance graduate scholarships supported E.L.L.C. Juvenile cod field research and data analysis over 22 yr was supported variously by funding and in-kind support from DFO (Productive Capacity Program, Environmental Science Strategic Research Fund, Atlantic Cod Science Program, Strategic Program for Ecosystem Research and Advice, Marine Conservation Targets Program, Centre of Expertise for Aquatic Habitat Research), NSERC (Canadian Healthy Oceans Network [CHONe-I \& II] network grants and 2 strategic project grants), Environment Canada (Environmental Innovations Program - Green Plan), Parks Canada (Protected Areas Program, Species-at-Risk Fund), Memorial University of Newfoundland, and INREST (representing the Port of Sept-Îles and City of Sept-îles). Age-3 cod data over the period was provided by DFO St. John's (Aquatic Resources Division). We thank over 200 MUN graduate and senior undergraduate students, DFO technical and biological support personnel, Parks Canada staff and other volunteers who contributed to this 25 yr time series, and especially appreciate the coordinating efforts of Dr. V. Gotceitas, S. Fraser, Dr. B. Laurel, J. Linehan, M. Thistle, M. Ryan, Dr. C. Morris, B. Newton and K. Dalley. D. Ings coordinated data provision from DFO research vessel surveys. We thank D. Quinn, E. Geissinger, and E. MacRobert for their input on this study. The manuscript benefitted from the comments of Dr. Jonathan Fisher, Dr. Ian Fleming, and anonymous reviewers on earlier drafts.

\section{LITERATURE CITED}

André C, Svedäng H, Knutsen H, Dahle G and others (2016) Population structure in Atlantic cod in the eastern North Sea-Skagerrak-Kattegat: early life stage dispersal and adult migration. BMC Res Notes 9:63

* Beaugrand G, Brander KM, Lindley JA, Souissi S, Reid PC (2003) Plankton effect on cod recruitment in the North Sea. Nature 426:661-664

* Bradbury IR, Laurel BJ, Robichaud D, Rose GA and others (2008) Discrete spatial dynamics in a marine broadcast spawner: re-evaluating scales of connectivity and habitat associations in Atlantic cod (Gadus morhua L.) in coastal Newfoundland. Fish Res 91:299-309

Bradford MJ (1992) Precision of recruitment predictions from early life stages of marine fishes. Fish Bull 90: 439-453

Brattey J (1999) Stock structure and seasonal migration patterns of Atlantic cod (Gadus morhua) based on inshore tagging experiments in Divs. 3KL during 1995-97. Can Stock Assess Secr Res Doc 99/103. DFO, Ottawa

Brattey J, Healey B, Porter D (2008) Northern cod (Gadus morhua) 16 years after the moratorium: new information from tagging and acoustic telemetry. Can Sci Advis Secr Res Doc 2008/047. DFO, Ottawa

* Britten GL, Dowd M, Worm B (2016) Changing recruitment capacity in global fish stocks. Proc Natl Acad Sci USA 113:134-139

* Campana SE (1996) Year-class strength and growth rate in young Atlantic cod Gadus morhua. Mar Ecol Prog Ser 135:21-26

Cooke ELL (2019) The influence of spatial and temporal scale in detecting offshore recruitment signals of Atlantic cod (Gadus mohua) based on coastal juvenile surveys. MSc thesis, Memorial University of Newfoundland, St. John's 
Copeman LA, Parrish CC, Gregory RS, Wells JS (2008) Decreased lipid storage in juvenile Atlantic cod (Gadus morhua) during settlement in cold-water eelgrass habitat. Mar Biol 154:823-832

Copes P (1996) Social impacts of fisheries management regimes based on individual quotas. Discussion Paper Series 96-2. Simon Fraser University, Burnaby

Cote D, Moulton S, Scruton DA, McKinley RS (2001) Microhabitat use of juvenile Atlantic cod in a coastal area of Bonavista Bay, Newfoundland. Trans Am Fish Soc 130: 1217-1223

Cote D, Moulton S, Frampton PC, Scruton DA, McKinley RS (2004) Habitat use and early winter movements by juvenile Atlantic cod in a coastal area of Newfoundland. J Fish Biol 64:665-679

Cote D, Gregory RS, Stewart HMJ (2008) Size-selective predation by river otter (Lontra canadensis) improves refuge properties of shallow coastal marine nursery habitats. Can J Zool 86:1324-1328

Cote D, Gregory RS, Morris CJ, Newton BH, Schneider DC (2013) Elevated habitat quality reduces variance in fish community composition. J Exp Mar Biol Ecol 440:22-28

* Cushing D (1990) Plankton production and year-class strength in fish populations: an update of the match/mismatch hypothesis. Adv Mar Biol 26:249-293

Daewel U, Schrum C, Gupta AK (2015) The predictive potential of early life stage individual-based models (IBMs): an example for Atlantic cod Gadus morhua in the North Sea. Mar Ecol Prog Ser 534:199-219

Dalley EL, Anderson JT (1997) Age-dependent distribution of demersal juvenile Atlantic cod (Gadus morhua) in inshore/offshore northeast Newfoundland. Can J Fish Aquat Sci 54:168-176

Davidson FJM, deYoung B (1995) Modelling advection of cod eggs and larvae on the Newfoundland Shelf. Fish Oceanogr 4:33-51

* deYoung B, Rose GA (1993) On recruitment and distribution of Atlantic cod (Gadus mohua) off Newfoundland. Can J Fish Aquat Sci 50:2729-2741

DFO (Fisheries and Oceans Canada) (2009) Does eelgrass (Zostera marina) meet the criteria as an ecologically significant species? Can Sci Advis Secr Sci Advis Rep 2009/ 018. DFO, Ottawa

DFO (2016) Stock assessment of Northern (2J3KL) cod in 2016. Can Sci Advis Secr Sci Advis Rep 2016/026. DFO, Ottawa

DFO (2019) Oceanographic conditions in the Atlantic zone in 2018. Can Sci Advis Sec Sci Advis Rep 2019/034. DFO, Ottawa

Drinkwater KF (2005) The response of Atlantic cod (Gadus morhua) to future climate change. ICES J Mar Sci 62: 1327-1337

Espeland SH, Thoresen AG, Olsen EM, Stige LC, Knutsen H, Gjøsæter J, Stenseth NC (2010) Diel vertical migration patterns in juvenile cod from the Skagerrak coast. Mar Ecol Prog Ser 405:29-37

Friedland KE, Hare JA, Wood GB, Col LA and others (2008) Does the fall phytoplankton bloom control recruitment of Georges Bank haddock Melanogrammus aeglefinus, through parental condition? Can J Fish Aquat Sci 65: 1076-1086

Fuentes-Yaco C, Mowbray F, Murphy H, Pepin P, Ringuette M, Caverhill C, Clay S (2020) Influence of plankton and environment on condition and abundance of capelin. Can Tech Rep Fish Aquat Sci 3363. DFO, Ottawa
Geissinger E, Gregory RS, Laurel BJ, Snelgrove PVR (2021) Food and initial size influence overwinter survival and condition of a juvenile marine fish (age-0 Atlantic cod). Can J Fish Aquat Sci 78:472-482

Gillanders BM, Able KW, Brown JA, Eggleston DB, Sheridan PF (2003) Evidence of connectivity between juvenile and adult habitats for mobile marine fauna: an important component of nurseries. Mar Ecol Prog Ser 247:281-295

GlobColour (2007) GC-PL-NIVA-FVR-01, issue 1-rev. 1. http://www.globcolour.info (accessed 17 November 2017)

Gorman AM, Gregory RS, Schneider DC (2009) Eelgrass patch size and proximity to the patch edge affect predation risk of recently settled age 0 cod (Gadus). J Exp Mar Biol Ecol 371:1-9

Gotceitas V, Fraser S, Brown JA (1997) Use of eelgrass beds (Zostera marina) by juvenile Atlantic cod (Gadus morhua). Can J Fish Aquat Sci 54:1306-1319

*Gregory RS, Anderson JT (1997) Substrate selection and use of protective cover by juvenile Atlantic cod Gadus morhua in inshore waters of Newfoundland. Mar Ecol Prog Ser 146:9-20

Gregory RS, Morris C, Newton B, Sargent P (2016) Relative strength of the 2010, 2011 and 2012 year classes, from nearshore surveys of demersal age 0 and 1 Atlantic cod in Newman Sound, Bonavista Bay. Can Sci Advis Secr Res Doc 2016/081. DFO, Ottawa

*Guisan A, Zimmermann NE (2000) Predictive habitat distribution models in ecology. Ecol Modell 135:147-186

Gulland JA (1989) Fish populations and their management. J Fish Biol 35:1-9

Hjort J (1914) Fluctuations in the great fisheries of northern Europe viewed in the light of biological research. Rapp P-V Reùn Cons Int Explor Mer 20:1-228

Horne JB, Bradbury IR, Paterson IG, Hardie D and others (2016) Complex post-larval dispersal processes in Atlantic cod revealed by age-based genetics and relatedness analysis. Mar Ecol Prog Ser 556:237-250

*Houde ED (2008) Emerging from Hjort's shadow. J Northwest Atl Fish Sci 41:53-70

ICES (International Council for the Exploration of the Sea) (2017) Report of the working group on assessment of demersal stocks in the North Sea and Skagerrak. Copenhagen, 26 April-5 May 2017. ICES, Copenhagen

Ings DW, Schneider DC, Methven DA (1997) Detection of a recruitment signal in juvenile Atlantic cod (Gadus morhua) in coastal nursery areas. Can J Fish Aquat Sci 54:25-29

'Ings DW, Gregory RS, Schneider DC (2008) Episodic downwelling predicts recruitment of Atlantic cod, Greenland cod and white hake to Newfoundland coastal waters. J Mar Res 66:529-561

Jackson EL, Rowden AA, Attrill M (2001) The importance of seagrass beds as habitat for fishery species. Oceanogr Mar Biol Annu Rev 39:269-303

Johnson C, Devred E, Casault B, Head E, Spry J (2018) Optical, chemical, and biological oceanographic conditions on the Scotial Shelf and in the Eastern Gulf of Maine in 2016. Can Sci Advis Secr Res Doc 2018/017. DFO, Ottawa

Kristiansen T, Drinkwater KF, Lough RG, Sundby S (2011) Recruitment variability in North Atlantic cod and matchmismatch dynamics. PLOS ONE 6:e17456

Laurel BJ, Gregory RS, Brown JA (2003a) Predator distribution and habitat patch area determine predation rates on Age-0 juvenile cod Gadus spp. Mar Ecol Prog Ser 251: 245-254 
Laurel BJ, Gregory RS, Brown JA (2003b) Settlement and distribution of Age-0 juvenile cod, Gadus morhua and G. ogac, following a large-scale habitat manipulation. Mar Ecol Prog Ser 262:241-252

Laurel BJ, Knoth BA, Ryer CH (2016) Growth, mortality, and recruitment signals in age- 0 gadids settling in coastal Gulf of Alaska. ICES J Mar Sci 73:2227-2237

Laurel BJ, Cote D, Gregory RS, Rogers L, Olsen EM (2017) Recruitment signals in juvenile cod surveys depend on thermal growth conditions. Can J Fish Aquat Sci 74: 511-523

Leaf RT, Friedland KD (2014) Autumn bloom phenology and magnitude influence haddock recruitment on Georges Bank. ICES J Mar Sci 71:2017-2025

Lilley RJ, Unsworth RKF (2014) Atlantic cod (Gadus morhua) benefits from the availability of seagrass (Zostera marina) nursery habitat. Glob Ecol Conserv 2:367-377

Linehan JE, Gregory RS, Schneider DC (2001) Predation risk of age-0 cod (Gadus) relative to depth and substrate in coastal waters. J Exp Mar Biol Ecol 263:25-44

Lomond TM, Schneider DC, Methven DA (1998) Transition from pelagic to benthic prey for age group 0-1 Atlantic cod, Gadus morhua. Fish Bull 96:908-911

Maritorena S, Siegel DA (2005) Consistent merging of satellite ocean color data sets using a bio-optical model. Remote Sens Environ 94:429-440

* Maritorena S, Hembise O, Mangin A, Siegel DA (2010) Remote sensing of environment merged satellite ocean color data products using a bio-optical model: characteristics, benefits and issues. Remote Sens Environ 114: 1791-1804

Mello, LGS, Rose, GA (2008) An acoustic-trawl survey of offshore over-wintering Northern cod, February-March 2007. Can Sci Advis Secr Res Doc 2008/048. DFO, Ottawa

Methven DA, Bajdik C (1994) Temporal variation in size and abundance of juvenile Atlantic cod (Gadus morhua) at an inshore site off eastern Newfoundland. Can J Fish Aquat Sci 51:78-90

Otterlei E, Nyhammer G, Folkvord A, Stefansson SO (1999) Temperature- and size-dependent growth of larval and early juvenile Atlantic cod (Gadus morhua): a comparative study of Norwegian coastal cod and northeast Arctic. Can J Fish Aquat Sci 56:2099-2111

* Ottersen G, Stige LC, Durant JM, Chan K, Rouyer TA, Drinkwater KF, Stenseth NC (2013) Temporal shifts in recruitment dynamics of North Atlantic fish stocks: effects of spawning stock and temperature. Mar Ecol Prog Ser 480:205-225

Pihl L, Ulmestrand M (1993) Migration pattern of juvenile cod (Gadus morhua) on the Swedish west coast. ICES J Mar Sci 50:63-70

* Planque B, Fredou T (1999) Temperature and the recruitment of Atlantic cod (Gadus morhua). Can J Fish Aquat Sci 56:2069-2077

* Platt T, Fuentes-Yaco C, Frank KT (2003) Spring algal bloom and larval fish survival. Nature 423:398-399

R Development Core Team (2017) R: a language and environment for statistical computing. R Foundation for Statistical Computing, Vienna

Renkawitz MD, Gregory RS, Schneider DC (2011) Habitat dependant growth of three species of bottom settling fish in a coastal fjord. J Exp Mar Biol Ecol 409:79-88

Robichaud D, Rose GA (2004) Migratory behaviour and range in Atlantic cod: inference from a century of tagging. Fish Fish 5:185-214
Robichaud D, Rose GA (2006) Density-dependent distribution of demersal juvenile Atlantic cod (Gadus morhua) in Placentia Bay, Newfoundland. ICES J Mar Sci 63: 766-774

Rogers LA, Stige LC, Olsen EM, Knutsen H, Chan K, Stenseth NC (2011) Climate and population density drive changes in cod body size throughout a century on the Norwegian coast. Proc Natl Acad Sci USA 108: 1961-1966

Kose GA, Rowe S (2015) Northern cod comeback. Can J Fish Aquat Sci 72:1789-1798

Rose GA, Rowe S (2018) Does redistribution or local growth underpin rebuilding of Canada's Northern cod? Can J Fish Aquat Sci 75:825-835

* Ruzzante DE, Taggart CT, Cook D, Goddard S (1996) Genetic differentiation between inshore and offshore Atlantic cod (Gadus morhua) off Newfoundland: microsatellite DNA variation and antifreeze level. Can J Fish Aquat Sci 53:634-645

* Sætre R, Toresen R, Anker-Nilssen T (2002) Factors affecting the recruitment variability of the Norwegian springspawning herring (Clupea harengus L.). ICES J Mar Sci 59:725-736

Sale PF, Doherty PJ, Eckert GJ, Douglas WA, Ferrell DJ (1984) Large scale spatial and temporal variation in recruitment to fish populations on coral reefs. Oecologia 64:191-198

Sissenwine MP (1984) The uncertain environment of fishery scientists and managers. Mar Resour Econ 1:1-30

Skern-Mauritzen M, Ottersen G, Handegard NO, Huse G, Dingsør GE, Stenseth NC, Kjesbu OS (2016) Ecosystem processes are rarely included in tactical fisheries management. Fish Fish 17:165-175

* Sogard SM, Olla BL (1993) The influence of predator presence on utilization of artificial seagrass habitats by juvenile walleye pollock, Theragra chalcogrammu. Environ Biol Fishes 37:57-65

Steingrund P, Gaard E (2005) Relationship between phytoplankton production and cod production on the Faroe Shelf. ICES J Mar Sci 62:163-176

* Stige LC, Hunsicker ME, Bailey KM, Yaragina NA, Hunt GL (2013) Predicting fish recruitment from juvenile abundance and environmental indices. Mar Ecol Prog Ser 480:245-261

* Taggart CT, Leggett WC (1987) Short-term mortality in post-emergent larval capelin Mallotus villosus. I. Analysis of multiple in situ estimates. Mar Ecol Prog Ser 41: 205-217

Taggart CT, Anderson J, Bishop C, Colbourne E and others (1994) Overview of cod stocks, biology, and environment in the Northwest Atlantic region of Newfoundland, with emphasis on Northern cod. ICES J Mar Sci Symp 198: 140-157

* Templeman W (1974) Migrations and intermingling of Atlantic cod (Gadus morhua) stocks of the Newfoundland area. J Fish Res Board Can 31:1073-1092

Thistle ME, Schneider DC, Gregory RS, Wells NJ (2010) Fractal measures of habitat structure: Maximum densities of juvenile cod occur at intermediate eelgrass complexity. Mar Ecol Prog Ser 405:39-56

* Tulk FJ, Cadigan NG, Brattey J, Robert D (2017) Spatial synchronicity in recruitment of Atlantic cod (Gadus morhua) stocks off Newfoundland and Labrador and the Flemish Cap. Fish Res 191:49-59

Tupper M, Boutilier RC (1995a) Effects of habitat on settle- 
ment, growth, and postsettlement survival of Alantic cod (Gadus morhua). Can J Fish Aquat Sci 52:1834-1841

Tupper M, Boutilier RG (1995b) Size and priority at settlement determine growth and competitive success of newly settled Atlantic cod. Mar Ecol Prog Ser 118: 295-300

Walsh SJ, McCallum BR (1997) Performance of the Campelen 1800 shrimp trawl during the 1995 Northwest Atlantic Fisheries Centre autumn groundfish survey. Northwest Atl Fish Organ Sci Council Stud 29:105-116 Walsh SJ, Hickey WH, Porter J, Delouche H, McCallum B (2009) NAFC survey trawl operations manual: version 1.0. DFO, St. John's

Editorial responsibility: Alejandro Gallego,

Aberdeen, UK

Reviewed by: 2 anonymous referees
Warren MA, Gregory RS, Laurel BJ, Snelgrove PVR (2010) Increasing density of juvenile Atlantic (Gadus morhua) and Greenland cod $(G$. ogac) in association with spatial expansion and recovery of eelgrass (Zostera marina) in a coastal nursery habitat. J Exp Mar Biol Ecol 394:154-160

Kabel RW, Levin PS, Tolimieri N, Mantua NJ (2011) Interactions between climate and population density in the episodic recruitment of bocaccio, Sebastes paucispinis, a Pacific rockfish. Fish Oceanogr 20:294-304

Z Zhang F, Reid KB, Nudds TD (2017) Relative effects of biotic and abiotic factors during early life history on recruitment dynamics: a case study. Can J Fish Aquat Sci 74: 1125-1134

Submitted: March 19, 2021

Accepted: June 25, 2021

Proofs received from author(s): August 21, 2021 